\title{
BMJ Open Efficacy of an educational intervention on students' attitudes regarding spirituality in healthcare: a cohort study in the USA
}

\author{
Zachary Paul Wargo Smothers, ${ }^{\oplus 1}$ Jennifer Young Tu, ${ }^{1}$ Colleen Grochowski, ${ }^{2}$ \\ Harold G Koenig ${ }^{3}$
}

To cite: Smothers ZPW, Tu JY, Grochowski C, et al. Efficacy of an educational intervention on students' attitudes regarding spirituality in healthcare: a cohort study in the USA. BMJ Open 2019;9:e026358. doi:10.1136/ bmjopen-2018-026358

- Prepublication history and additional material for this paper are available online. To view these files, please visit the journal online (http://dx.doi. org/10.1136/bmjopen-2018026358).

Received 29 August 2018 Revised 1 March 2019 Accepted 4 March 2019

Check for updates

(c) Author(s) (or their employer(s)) 2019. Re-use permitted under CC BY-NC. No commercial re-use. See rights and permissions. Published by BMJ.

${ }^{1}$ Doctor of Medicine Program, Duke University School of Medicine, Durham, North Carolina, USA

${ }^{2}$ Office of Curricular Affairs, Duke University School of Medicine, Durham, North Carolina, USA

${ }^{3}$ Psychiatry, Duke University, Durham, North Carolina, USA

Correspondence to

Zachary Paul Wargo Smothers: zachary.smothers@duke.edu

\section{ABSTRACT}

Objective To determine if an educational intervention focused on the role of spirituality in healthcare positively affects medical students' attitudes and perceptions relating to this topic.

Design A pre-post cohort study.

Setting An undergraduate medical institution affiliated with an academic medical center in the USA.

Participants A total of 110 medical students currently on their clinical rotations received the educational intervention, of whom 71 (65\%) completed both the presurvey and postsurvey. Demographic variables did not significantly differ from the national average of medical students, or from a comparison group. All students who attended the intervention were given the opportunity to participate in the survey.

Interventions The educational intervention consisted of a 60-minute lecture focusing on religion/spirituality $(\mathrm{R} / \mathrm{S})$ in healthcare, followed by a 90 -minute case discussion in a small group setting.

\section{Primary and secondary outcome}

measures Assessment consisted of 18-item preintervention and postintervention survey quantifying student's attitudes towards, comfort with, and perceptions of $R / S$ in healthcare.

Results Attitudes towards, comfort with, and perceptions of R/S in healthcare were generally positive preintervention. Following the intervention, students expressed an increased willingness to include $\mathrm{R} / \mathrm{S}$ competency in their future practice $(p=0.001)$, were more comfortable sharing their own R/S beliefs with a patient when appropriate $(p=0.02)$, and were more willing to approach a patient with $\mathrm{R} / \mathrm{S}$ concern $(\mathrm{p}=0.04)$. The other surveyed attitudes demonstrated positive, but nonsignificant improvement.

Conclusion An educational intervention focusing on approaching patients with $\mathrm{R} / \mathrm{S}$ concerns has the ability to improve the attitudes and comfort of medical students. By incorporating a total of 150 minutes of education about $\mathrm{R} / \mathrm{S}$, medical schools can help develop this particular area of cultural competence, preparing a generation of physicians to professionally approach R/S concerns of patients. Future research should move beyond quantifying attitudes and strive to understand changes in knowledge and student behaviour.
Strengths and limitations of this study

- An author developed survey that was designed around empirical literature and expert opinion.

- A cohort study using a non-intervention group for baseline comparison.

- A novel educational intervention focusing on the role of religion/spirituality in medicine.

- An appropriate sample size consisting of a representative sample.

- Measurement of attitudes, but not knowledge or behaviours.

\section{INTRODUCTION}

Physicians in the USA face the challenging scenario of caring for an increasingly diverse population. ${ }^{1}$ One avenue for addressing this diversity is by training physicians in culturally competent care. ${ }^{2-4}$ The Accreditation Council for Graduate Medical Education lists cultural competency (or cultural sensitivity) as one of the core requirements for residents. $^{23}$ Medical schools are expected to instruct students in cultural competency, and are provided suggestions on how to incorporate this care. ${ }^{4}$ Evidence has shown that cultural competent care improves both patient outcomes and patient perceptions of care ${ }^{5-7}$ Part of cultural competency is the ability to respect the religious/spiritual $(\mathrm{R} / \mathrm{S})$ expressions of their patients ${ }^{2-4}$. With nearly $1 / 5$ of the USA population being raised in interfaith homes, ${ }^{8}$, physicians will need to continue to develop these skills.

Previous research has explored the efficacy of educational interventions on medical students' knowledge and attitudes about R/S in healthcare. ${ }^{9-17}$ Additional reports detail medical students' support for $\mathrm{R} / \mathrm{S}$ educational interventions. ${ }^{9} 18$ Similar findings have been reported for other health professionals and graduate medical education. ${ }^{19-23}$ Despite 
this support, R/S education has not been incorporated into undergraduate medical curriculum in a comprehensive way. ${ }^{24}$

Practicing physicians feel that $\mathrm{R} / \mathrm{S}$ concerns in patients should be addressed and believe that they improve patient outcomes, but less than $20 \%$ routinely inquire about these issues, citing a lack of knowledge, training and time to do so. ${ }^{25-32}$ Patient outcomes may be negatively affected by this trend as addressing $\mathrm{R} / \mathrm{S}$ concerns has been directly tied to improved patient outcomes. ${ }^{3133-41}$

One potential avenue for addressing the reported gap in physician's knowledge and skills relating to $\mathrm{R} / \mathrm{S}$ concerns is to educate medical students on their clinical rotations. Previous work from this group has found that medical students encounter a diverse range of experiences with $\mathrm{R} / \mathrm{S}$ and may not feel prepared to approach them (Smothers et al, unpublished data). Part of this hesitancy may stem from the ethical considerations that come from discussing a patient's R/S. Previously published literature has mainly focused on discovering students' knowledge or attitudes about this topic, without an educational intervention. The aim of this study was to establish the feasability and assess the efficacy of an educational intervention on attitudes of medical students relating to $\mathrm{R} / \mathrm{S}$ in healthcare.

\section{METHOD}

A novel educational intervention relating to $\mathrm{R} / \mathrm{S}$ in medicine was developed and implemented with second year medical students (currently on their clinical rotations) at the Duke University School of Medicine. This intervention took place during the students' 'Clinical Skills Foundation' course in April 2018. The survey used to evaluate this intervention was also administered to a separate group of medical students who had not received this lecture, in order to compare baseline statistics. This group of students were matriculated at the same institution, had completed all their clinical rotations, and were currently participating in a research year.

We used a pre-post study design to determine the effectiveness of this curriculum (Supplemental Digital Content, online supplementary figure 1) on the confidence, attitudes and interests in $\mathrm{R} / \mathrm{S}$ of medical students. This curriculum evaluation received exempt status from the Duke Health Institutional Review Board.

\section{Survey design}

We developed and administered a preintervention survey to determine medical students' baseline confidence, attitudes and interests in $\mathrm{R} / \mathrm{S}$. To begin, the authors consulted an expert in the field of $\mathrm{R} / \mathrm{S}$ in medicine to discover 'major themes' that are core to this field. After this, a preliminary survey was constructed using literature review of prior methods for evaluating $\mathrm{R} / \mathrm{S}$ attitudes and feedback from the same expert. ${ }^{182542}$ Medical educational administrators at the Duke University School of Medicine were notified of the survey and offered a chance to weigh
Table 1 Self-identified demographic data for the surveyed groups

\begin{tabular}{|c|c|c|c|}
\hline \multirow{2}{*}{$\begin{array}{l}\text { Demographic } \\
\text { measurement }\end{array}$} & $\begin{array}{l}\text { Intervention } \\
\text { group }\end{array}$ & $\begin{array}{l}\text { Control } \\
\text { group }\end{array}$ & \multirow[b]{2}{*}{$P$ value } \\
\hline & No (\%) & No (\%) & \\
\hline \multicolumn{4}{|l|}{ Race/ethnicity } \\
\hline White & $40(48)$ & $31(37)$ & 0.1738 \\
\hline Asian & $21(25)$ & $12(14)$ & 0.8026 \\
\hline $\begin{array}{l}\text { Black/African- } \\
\text { American }\end{array}$ & $13(16)$ & $3(4)$ & 0.0876 \\
\hline $\begin{array}{l}\text { American Indian } \\
\text { and Alaska } \\
\text { native }\end{array}$ & $1(1)$ & 0 & 0.4295 \\
\hline $\begin{array}{l}\text { Native Hawaiian } \\
\text { and other Pacific } \\
\text { islander }\end{array}$ & 0 & 0 & $\mathrm{~N} / \mathrm{A}$ \\
\hline $\begin{array}{l}\text { Hispanic or } \\
\text { Latino }\end{array}$ & $3(4)$ & $2(24)$ & 0.9362 \\
\hline $\begin{array}{l}\text { Two or more } \\
\text { races/ethnicities }\end{array}$ & $5(6)$ & $2(2)$ & 0.5892 \\
\hline Not answered & $1(1)$ & $2(2)$ & 0.3077 \\
\hline Age & $25(\mathrm{SD}=1.58)$ & $26(S D=3.86)$ & $0.0201^{*}$ \\
\hline \multicolumn{4}{|l|}{ Gender } \\
\hline Female & $50(60)$ & $29(56)$ & 0.6672 \\
\hline Male & $33(39)$ & $22(42)$ & 0.7263 \\
\hline Not answered & $1(1)$ & $1(2)$ & 0.7279 \\
\hline \multicolumn{4}{|l|}{ Religious affiliation } \\
\hline Christian & $39(46)$ & $25(49)$ & 0.8493 \\
\hline Jewish & $4(5)$ & $5(10)$ & 0.2670 \\
\hline Muslim & $3(4)$ & $0(0)$ & 0.1676 \\
\hline Hindu & $5(6)$ & $2(4)$ & 0.5892 \\
\hline Buddhist & $0(0)$ & $1(2)$ & 0.2005 \\
\hline Atheist & $22(26)$ & $15(29)$ & 0.7279 \\
\hline Agonistic & $6(7)$ & $2(4)$ & 0.4295 \\
\hline Not answered & $5(6)$ & $2(4)$ & 0.5892 \\
\hline Total number & 84 & 52 & \\
\hline
\end{tabular}

*Denotes $\mathrm{P}<0.05$

in on the composition of the survey. We administered the survey approximately 5 minutes before the educational intervention and provided students with ample time to complete the survey, as well as to ask questions. The 'control' group of students came from upper level medical students who received the survey via email and were asked to participate. Neither group was required to participate in the study. Demographic information was collected and included self-identified gender, age, ethnicityand religious affiliation (table 1). We assessed attitudes, confidence, and interest through 18 multiple-choice questions on the benefits of, ethical considerations of, and interest in $\mathrm{R} / \mathrm{S}$ 's overlap with healthcare. Medical students were also asked to report perceived barriers to incorporating 
$\mathrm{R} / \mathrm{S}$ into healthcare and to speculate on their future practice. The administered survey was composed as a 10-point Likert-type scale ( $1=$ 'Not at All', $10=$ 'Very Much'). The precurriculum and postcurriculum surveys were identical, with questions in the same order, and delivered in the same electronic fashion. A copy of the survey is available as supplemental digital content (online supplementary survey instrument).

\section{Patient and public involvement}

Neither patients nor the public were involved in the design of the educational intervention, recruitment of participants or formulation of the survey. Participants were minimally burdened by the survey as it was completed in less than 5 minutes' time. The primary author on this manuscript is a medical student and helped design the survey in accordance with experiences commonly encountered during clinical rotations. Results of this study will be freely available to participants in an anonymous fashion on publication.

\section{R/S educational intervention development and administration}

Medical students had completed approximately 9 months of clinical rotations before the educational intervention was administered. Students received this intervention as part of their Clinical Skills Foundation class series, a mandatory weekly seminar that explores topics relevant to being a skilled physician. The intervention consisted of two parts: a 60 -minute lecture delivered by a content expert in a traditional didactic setting and a 90-minute small group, case-based discussion.

The lecture approached the professional and ethical considerations of $\mathrm{R} / \mathrm{S}$ by presenting two cases with the goal of answering the question: 'Is talking to patients about religious/spiritual concerns a necessary part of medicine, a transgression of professional boundaries, or something else?' The first case presented a patient who comes to clinic with a blood pressure of 210/130 and declines taking their antihypertensive medications, instead choosing to 'trust God with their health' and refusing to trust medicine over 'Him.' The second case was a patient who recently underwent a Whipple procedure for pancreatic cancer. When the surgeon stops to check on the patient, the family asks the physicians to pray for the patient's recovery.

These cases were used to approach three norms in medicine (competency, autonomy and neutrality) ${ }^{43}$ and their relation to R/S concerns. Competency refers to the physician's skill in approaching $\mathrm{R} / \mathrm{S}$ concerns and recognising the boundaries of their training and confidence in addressing these concerns. This can also relate to the understanding that other professions (such as a trained healthcare chaplain) may be more competent than the physician in this matter. Autonomy emphasises the patient's choice in their treatment in the context of an inherent power dynamic between patients and physicians. Identifying this dynamic is an important part of R/S care in medicine and is mentioned to highlight the patient's decision-making capabilities, even when they directly conflict with 'evidencebased medicine.' The final concept is neutrality, which references the belief that physicians are professionals who serve a diverse public; they must remain neutral on topics such as religion.

Students were then presented with two cases in which physicians attempted to approach an R/S concern and did so in a non-professional way. Both cases were realworld situations that occurred when physicians prayed with a patient without permission. These two cases highlighted the harm that can come when these three norms are not respected, or when the physician is approaching these concerns for personal reasons. This topic was used to transition into a short section discussing the current state of $\mathrm{R} / \mathrm{S}$ care in medicine. During this time, the lecturer discussed current literature supporting patient desires for physicians to address R/S concerns and physicians actively avoiding this topic. ${ }^{25-32}$

The final portion of the lecture was used to present students with ways to approach $\mathrm{R} / \mathrm{S}$ concerns while respecting the three norms of medicine. It was suggested that competence can be transformed into 'wisdom' and clinical judgement, based on the situation. Autonomy can be re-worded as 'respect' and hinges on the physician respecting the patient's wishes, beliefs and faith. Neutrality can be interpreted as 'candour,' with the possibility of respectfully disclosing their reasons for agreeing or disagreeing with their patient's decision, without manipulating the patient. Following this discussion, the two original cases were revisited, and students were asked to reflect on them with the framework they had been given.

The 90-minute case discussion was executed in small groups (each of roughly $6-10$ students) that were pre-determined. These small groups were an existing component of the Clinical Skills Foundation course, and students had been in the same groups for roughly 2years. Each group had a small group instructor who had been appointed by the Clinical Skills Foundation faculty. These leaders were provided with a list of cases to discuss with their groups, invoking student reflection and opinions. Instructors were expected to mentor students in the ethical considerations and provide them with resources for professional judgement.

\section{Evaluation and statistical analysis}

We evaluated the efficacy of this educational intervention using a preintervention and postintervention survey, developed as described above. Confidentiality was preserved by not including name, student ID number, or other identifying information in the survey. Respecting the sensitive and personal nature of $\mathrm{R} / \mathrm{S}$, demographic results were aggregated and associations between genders, ethnic groups, age or religious affiliation were not made. Our results were exported from the Qualtrics platform (Qualtrics, Provo, Utah, USA) and imported into Graphpad Prism V.7 (GraphPad Software, La Jolla, California, USA) for analysis. We used descriptive statistics (mean and SD) to describe baseline characteristics 
of both the groups, as well as postintervention results of the intervention group. Additionally, our data indicated that attitude, confidence, and interest scores from pre to post were not normally distributed, and thus were also assessed using the Wilcox signed-rank test. Comparison of pretest scores among the intervention and control groups also appeared non-normally distributed and was analysed using the Mann-Whitney test. Demographic similarity was compared using a $\chi^{2}$ test of independence and independent sample t-test. ${ }^{44}$

\section{RESULTS}

\section{Study participants}

An estimated 110 eligible medical students in their clinical rotations participated in the 1 hour lecture and 90 min case discussion. A total of $84(76 \%)$ provided their demographic information, $80(73 \%)$ answered the preintervention questions and 71 (65\%) completed both precurriculum and postcurriculum surveys. Of these, $60 \%$ (50 out of 84 ) were female, $48 \%$ (40 out of 84 ) were Caucasian, and 46\% (39 out of 84) were Christian (table 1). Thus, respondents were of comparable age, gender, and ethnic backgrounds to those reported by the 2017 Association of American Medical Colleges Graduation Questionnaire. ${ }^{45} 52$ students who had completed their clinical rotations without participating in the $\mathrm{R} / \mathrm{S}$ curriculum submitted a precurriculum survey, which served as our control; respondents were of similar demographic composition to that described above, with the exception of age $(p=0.0201$, table 1$)$. The intervention group's preintervention scores did not vary significantly from the control group's scores (table 2).

\section{Survey data: ethical and professional education}

The most statistically significant change in students' attitudes towards $\mathrm{R} / \mathrm{S}$ in healthcare was observed in their increased willingness to include $\mathrm{R} / \mathrm{S}$ in future practice following the curriculum (mean composite score pre 5.34 , post $6.59, \mathrm{p}=0.0013$; table 3 , item 15 ).

Students also showed significant improvements in understanding of $\mathrm{R} / \mathrm{S}$ in clinical practice. To a greater degree, students agreed with the statement that it is appropriate for a physician to share their own religious/spiritual beliefs with a patient' (mean composite score pre 3.95 , post $4.76, \mathrm{p}=0.02$; table 3 , item 7 ), in

Table 2 Comparison of preintervention responses between control and intervention group

Preintervention mean scores (SD)

\begin{tabular}{|c|c|c|c|}
\hline & $\begin{array}{l}\text { Intervention } \\
\text { group }\end{array}$ & Control group & $P$ value \\
\hline 1. R/Shas a place in healthcare. & $7.35(1.92)$ & $7.09(2.13)$ & 0.5671 \\
\hline 3. Discussing a patient's R/Scould improve their care. & $7.91(3.63)$ & $8.07(1.81)$ & 0.5919 \\
\hline 4. R/S can influence a patient's outcomes. & $7.50(1.92)$ & $7.68(2.13)$ & 0.4722 \\
\hline 6. Patients want their physician to discuss their R/S. & $5.91(1.87)$ & $6.13(1.82)$ & 0.3272 \\
\hline $\begin{array}{l}\text { 7. It is appropriate for a physician to share their own religious/ } \\
\text { spiritual beliefs with a patient. }\end{array}$ & $3.95(2.07)$ & $3.67(1.98)$ & 0.3809 \\
\hline $\begin{array}{l}\text { 8. It is appropriate for a physician to pray with a patient (if the patient } \\
\text { requests it). }\end{array}$ & $7.19(2.37)$ & $7.40(2.31)$ & 0.7896 \\
\hline 12. I can discuss R/S with patients of different or no faiths. & $6.44(2.37)$ & $6.46(2.72)$ & 0.8809 \\
\hline 13. I would avoid discussing R/S with a patient due to ethical concerns. & $4.46(1.95)$ & $4.18(2.05)$ & 0.3291 \\
\hline 14. I will have time to discuss $\mathrm{R} / \mathrm{S}$ with my patient. & $4.25(1.98)$ & $3.91(1.85)$ & 0.4825 \\
\hline $\begin{array}{l}\text { 15. I will include religiously/spiritually competent care into my future } \\
\text { practice. }\end{array}$ & $5.34(2.38)$ & $5.62(2.47)$ & 0.3649 \\
\hline $\begin{array}{l}\text { 16. I will suggest other physicians or students include religiously/ } \\
\text { spiritually competent care into their current/future medical practice. }\end{array}$ & $5.10(2.43)$ & $4.84(2.76)$ & 0.7035 \\
\hline 17. I will enjoy working with religious/spiritual patients. & $6.49(2.40)$ & $6.78(2.26)$ & 0.7801 \\
\hline
\end{tabular}

$\mathrm{R} / \mathrm{S}$, religion/spirituality. 
Table 3 Preintervention and postintervention score means, SD, p values and number of responses

\section{Preintervention and postintervention scores}

\begin{tabular}{|c|c|c|c|}
\hline & $\begin{array}{l}\text { Preintervention } \\
\text { Mean (SD) }\end{array}$ & $\begin{array}{l}\text { Postintervention } \\
\text { Mean (SD) }\end{array}$ & P value \\
\hline 1. R/S has a place in healthcare. & $7.35(1.92)$ & $7.81(1.83)$ & 0.1234 \\
\hline 3. Discussing a patient's R/Scould improve their care. & $7.91(3.63)$ & $8.00(1.79)$ & 0.5828 \\
\hline 4. R/S can influence a patient's outcomes. & $7.50(1.92)$ & $7.61(2.15)$ & 0.7365 \\
\hline $\begin{array}{l}\text { 7. It is appropriate for a physician to share their own religious/spiritual beliefs } \\
\text { with a patient. }\end{array}$ & $3.95(2.07)$ & $4.76(2.39)$ & $0.0196^{*}$ \\
\hline $\begin{array}{l}\text { 8. It is appropriate for a physician to pray with a patient (if the patient } \\
\text { requests it). }\end{array}$ & $7.19(2.37)$ & $7.58(2.22)$ & 0.2145 \\
\hline 12. I can discuss R/S with patients of different or no faiths. & $6.44(2.37)$ & $6.76(2.18)$ & 0.2370 \\
\hline 13. I would avoid discussing R/S with a patient due to ethical concerns. & $4.46(1.95)$ & $3.85(1.84)$ & $0.0427^{*}$ \\
\hline 14. I will have time to discuss R/S with my patient. & $4.25(1.98)$ & $4.77(1.80)$ & 0.2234 \\
\hline $\begin{array}{l}\text { 15. I will include religiously/spiritually competent care into my future } \\
\text { practice. }\end{array}$ & $5.34(2.38)$ & $6.592 .09)$ & $0.0013^{\star *}$ \\
\hline $\begin{array}{l}\text { 16. I will suggest other physicians or students include religiously/ } \\
\text { spiritually competent care into their current/future medical practice. }\end{array}$ & $5.10(2.43)$ & $5.83(2.58)$ & 0.0554 \\
\hline 17. I will enjoy working with religious/spiritual patients. & $6.49(2.40)$ & $6.94(2.24)$ & 0.1482 \\
\hline
\end{tabular}

$\mathrm{R} / \mathrm{S}$, religion/ spirituality.

concordance with the professional acceptability of $\mathrm{R} / \mathrm{S}$ conversations presented in the curriculum. Students expressed weaker agreement with the statement, 'I would avoid discussing religion/spirituality with a patient due to ethical concerns' (mean composite score pre 4.46, post $3.85, \mathrm{p}=0.04$; table 3 , item 13 ), after the intervention, suggesting a better understanding that $\mathrm{R} / \mathrm{S}$ conversations with patients are ethically acceptable. There were non-significant improvements in students' acknowledgement of the beneficial role, professional acceptability, and comfort with their use of $\mathrm{R} / \mathrm{S}$ in healthcare (table 3).

\section{DISCUSSION}

Comprehensive education relating to $\mathrm{R} / \mathrm{S}$ in healthcare is overlooked by most cultural competency curricula. ${ }^{24}$ By implementing a 60-minute lecture and 90-minute case discussion with a content expert physician, and developing presurvey and postsurvey, we demonstrated improvements in medical students' understanding of $\mathrm{R} / \mathrm{S}$ in clinical practice. To our knowledge, this is one of the first trials to develop an educational intervention focused on this complex but important topic. While this was a pilot study at a single educational institution, we believe this intervention is a feasible model that may be easily adapted and replicated in other medical schools. This claim is supported by the fact that our respondent demographics were similar to that of the national average. ${ }^{46}$

$\mathrm{R} / \mathrm{S}$ in healthcare is a seldom taught subject, and practical applications to patient interactions are a challenging task, especially when considering ethical concerns. ${ }^{24} 4647$ At baseline, students expressed some uncertainty about the ethical and professional acceptability of $\mathrm{R} / \mathrm{S}$ in healthcare, demonstrated by mean composite pre-curriculum scores of 4-6 for items such as 'it is appropriate for a physician to inquire about a patient's R/S' (mean composite 6.01; table 3, item 5). In addition to this uncertainty, students expressed discomfort with or lack of confidence in completing $\mathrm{R} / \mathrm{S}$ tasks in clinical practice, demonstrated by low mean composite pre-curriculum scores for items such as 'I will have time to discuss $\mathrm{R} / \mathrm{S}$ with my patient' (mean composite 4.25; table 3, item 14). This suggests that medical students at this stage have little exposure to $\mathrm{R} / \mathrm{S}$ education and practice. To our knowledge, this is the first study to report the effects of a targeted educational 
intervention for students currently in their clinical rotations.

Improvement was seen in mean composite scores of all items regarding the professional and ethical acceptability of $\mathrm{R} / \mathrm{S}$ tasks in healthcare, including inquiring about a patient's $\mathrm{R} / \mathrm{S}$ and praying with a patient on request, with a statistically significant effect on the students' attitudes towards physicians sharing their own $\mathrm{R} / \mathrm{S}$ beliefs with a patient (mean composite score pre 3.95, post $4.76, \mathrm{p}=0.02$; table 3 , item 7 ). While significant, this measure still falls below the neutral score of ' 5 .' This may represent a shift toward 'neutral' feelings rather than an increase in 'positive' feelings. When asked directly about their own practice, students suggested a significantly increased willingness to discuss $\mathrm{R} / \mathrm{S}$ with a patient, due to an enhanced ethical understanding (mean composite score pre 4.46, post 3.85, $\mathrm{p}=0.04$; table 3 , item 13 ).

The educational intervention had a positive impact on not only understanding, but also motivation. There was a highly significant increase in students' commitment to including ' $\mathrm{R} / \mathrm{S}$ competent care' in future practice (mean composite score pre 5.34, post $6.59, \mathrm{p}=0.0013$; table 3, item 15), with a close to significant increase in those willing to suggest other physicians or students do the same (mean composite score pre 5.10, post 5.83, $\mathrm{p}=0.055$ ). This suggests that the lecture and case discussion may not only be an effective educational tool, but also a starting point for greater engagement with $\mathrm{R} / \mathrm{S}$ tasks in a budding generation of physicians.

The results of this study should be viewed within the greater context of the healthcare field, in which other professions are beginning to make similar recommendations for the education of their learners. For example, schools of public health have developed several different approaches for teaching $\mathrm{R} / \mathrm{S}$ in healthcare. ${ }^{48}$ Additionally, schools of pharmacy and schools of nursing have begun to conduct research into the knowledge and attitudes of their learners towards $\mathrm{R} / \mathrm{S}$ in healthcare, paving the way for future interventions. ${ }^{49} 50$ The present study, understood in this context, will help medical education continue to improve in this interprofessional endeavour to properly and sensitively address religious and spiritual factors in education and practice.

\section{LIMITATIONS}

These results should be considered with the acknowledgement of several limitations, the first and most important being a reliance on self-reported data. When compared with a control group of their peers, our intervention group did not vary significantly in baseline response, removing some risk of selection bias. However, self-selection bias could have resulted from demographic factors specific to the single medical school included, as well as our dependence on a convenience sample of students willing to participate in this online survey. This limitation may influence the generalisability of these findings to medical students in other locations around the world, and therefore these findings should be considered preliminary. Future studies might consider conducting more in-depth qualitative interviews with students or direct observation, to provide more robust insights for developing R/S curricula. Second, results were composite changes in survey responses on a 0-10 scale, allowing quantitative but limiting qualitative analyses. Hence, while we were able to observe the presence of general trends in the students surveyed, it was not possible to explain the reasons for these changes, and our discussion relied on the precise wording of survey items. Third, the postsurvey evaluated the immediate effect of our education intervention (up to 1 week after the class), with survey items beginning with an 'I will' stem serving as a proxy for long-term effects. Future studies should consider follow-up with students during their future clinical rotations or careers, to more accurately assess whether there was a longer-term impact.

While 17 out of 18 survey items showed improvements in attitudes towards, understanding of, and motivation to apply R/S in healthcare, the last item seemed to suggest no effect on, or even a slight decrease in, students' motivation to learn more about the subject (mean composite score pre 7.19 , post $6.97, \mathrm{p}=0.38$; table 3 , item 18 ). Our next steps include improving the curriculum to promote further curiosity and engagement, and subsequently, to provide and evaluate the educational materials at other institutions. We also hope that future studies will pursue the effects of the intervention on long-term clinical practice, demonstrating improvements in the performance of specific R/S tasks.

\section{CONCLUSION}

In summary, our novel curriculum is an educational intervention to teach medical students in their clinical rotations about the ethical and professional role of $\mathrm{R} / \mathrm{S}$ in healthcare. This first iteration significantly improved medical student knowledge and attitudes about ethical considerations in $\mathrm{R} / \mathrm{S}$, demonstrating feasibility and efficacy within a reasonable timeframe. By promoting R/S early in clinical training, such interventions can improve cultural competency in an important and often overlooked aspect of healthcare and benefit both patients and providers.

Acknowledgements The authors wish to thank Dr. Farr Curlin for his development and administration of the educational intervention.

Contributors ZPWS made substantial contributions to conception, design, acquisition and analysis of data, writing and editing of this manuscript. JYT made substantial contributions to acquisition and analysis of data, writing and editing of this manuscript. CG made substantial contributions to the analysis of data, writing and editing of this manuscript. HGK made substantial contributions to conception, design, acquisition and analysis of data, writing and editing this of manuscript.

Funding The authors have not declared a specific grant for this research from any funding agency in the public, commercial or not-for-profit sectors.

Competing interests None declared.

Patient consent for publication Not required.

Ethics approval The authors obtained an "exempt" status by the Duke Health Institutional Review Board on April 5th, 2017 (ID: Pro00082734).

Provenance and peer review Not commissioned; externally peer reviewed. 
Data sharing statement The data are currently unavailable due to pending publications related to the same IRB protocol. On publication of all relevant article, the dataset will be made available to the public.

Open access This is an open access article distributed in accordance with the Creative Commons Attribution Non Commercial (CC BY-NC 4.0) license, which permits others to distribute, remix, adapt, build upon this work non-commercially, and license their derivative works on different terms, provided the original work is properly cited, appropriate credit is given, any changes made indicated, and the use is non-commercial. See: http://creativecommons.org/licenses/by-nc/4.0/.

\section{REFERENCES}

1. Vespa J, Armstrong DM, Medina L. Demographic Turning Points for the United States: Population Projections for 2020 to 2060.

2. Holmboe ES, Edgar L, Hamstra S. The Milestones Guidebook. ACGME Core Competencies2016. ACGME https://www.acgme.org/ Portals/O/MilestonesGuidebook.pdf (Accessed 6 Aug 2018).

3. ACGME Core Competencies: Professionalism and Quality Care. NEJM Knowledge. NEJM Knowledge. 2018 https://knowledgeplus. nejm.org/blog/acgme-core-competencies-professionalism/ (Accessed 6 Aug 2018).

4. Cultural Competence Education for Medical Students. Cultural Competency. Associate of American Medical Colleges. 2005. AAMC https://www.aamc.org/download/54338/data/ (Accessed 6 Aug 2018).

5. Ohana S, Mash R. Physician and patient perceptions of cultural competency and medical compliance. Health Educ Res 2015;30:923-34.

6. Truong M, Paradies Y, Priest N. Interventions to improve cultural competency in healthcare: a systematic review of reviews. BMC Health Serv Res 2014;14:99.

7. Horvat L, Horey D, Romios P, et al. Cultural competence education for health professionals. Cochrane Database Syst Rev 2014:CD009405.

8. Mitchell T. One-in-Five U.S. Adults Were Raised in Interfaith Homes. Pew Research Center's Religion \& Public Life Project. 2016 http:// www.pewforum.org/2016/10/26/one-in-five-u-s-adults-were-raisedin-interfaith-homes/ (Accessed 8 Dec 2018).

9. Guck TP, Kavan MG. Medical student beliefs: spirituality's relationship to health and place in the medical school curriculum. Med Teach 2006;28:702-7.

10. Mitchell CM, Epstein-Peterson ZD, Bandini J, et al. Developing a Medical School Curriculum for Psychological, Moral, and Spiritual Wellness: Student and Faculty Perspectives. J Pain Symptom Manage 2016;52:727-36.

11. Schonfeld TL, Schmid KK, Boucher-Payne D. Incorporating Spirituality into Health Sciences Education. J Relig Health 2016;55:85-96.

12. Loh KP, Ghorab H, Clarke E, et al. Perceptions, and Interest in Complementary and Alternative Medicine. The Journal of Alternative and Complementary Medicine 2013;19:360-6.

13. Perechocky A, DeLisser H, Ciampa R, et al. Piloting a medical student observational experience with hospital-based trauma chaplains. J Surg Educ 2014;71:91-5.

14. Paal $P$, Helo $Y$, Frick $E$. Spiritual care training provided to healthcare professionals: a systematic review. J Pastoral Care Counsel 2015;69:19-30.

15. Barnett KG, Fortin AH. Spirituality and medicine. J Gen Intern Med 2006;21:481-5.

16. Fortin $\mathrm{AH}$, Barnett KG. Studentjama. Medical school curricula in spirituality and medicine. JAMA 2004;291:2883.

17. Ledford CJ, Seehusen DA, Canzona MR, et al. Using a teaching OSCE to prompt learners to engage with patients who talk about religion and/or spirituality. Acad Med 2014;89:60-5.

18. Lucchetti G, de Oliveira LR, Koenig HG, et al. Medical students, spirituality and religiosity--results from the multicenter study SBRAME. BMC Med Educ 2013;13:162.

19. Saguil $A$, Fitzpatrick $A L$, Clark $G$. Are residents willing to discuss spirituality with patients? J Relig Health 2011;50:279-88.

20. Kattan W, Talwar V. Psychiatry residents' attitudes toward spirituality in psychiatry. Acad Psychiatry 2013;37:360.

21. Mthembu TG, Roman NV, Wegner L. A Cross-Sectional Descriptive Study of Occupational Therapy Students' Perceptions and Attitudes Towards Spirituality and Spiritual Care in Occupational Therapy Education. J Relig Health 2016;55:1529-45.

22. Lennon-Dearing R, Florence JA, Halvorson $\mathrm{H}$, et al. An interprofessional educational approach to teaching spiritual assessment. J Health Care Chaplain 2012;18(3-4):121-32.
23. Pike J. Spirituality in nursing: a systematic review of the literature from 2006-10. Br J Nurs 2011;20-743-9.

24. Koenig HG, Hooten EG, Lindsay-Calkins E, et al. Spirituality in medical school curricula: findings from a national survey. Int $J$ Psychiatry Med 2010;40:391-8.

25. Curlin FA, Chin MH, Sellergren SA, et al. The association of physicians' religious characteristics with their attitudes and selfreported behaviors regarding religion and spirituality in the clinical encounter. Med Care 2006;44:446-53.

26. Monroe $\mathrm{MH}$, Bynum D, Susi B, et al. Primary care physician preferences regarding spiritual behavior in medical practice. Arch Intern Med 2003;163:2751.

27. Anandarajah G, Hight E. Spirituality and medical practice: using the HOPE questions as a practical tool for spiritual assessment. Am Fam Physician 2001;63:31.

28. Ellis MR, Vinson DC, Ewigman B. Addressing spiritual concerns of patients: family physicians' attitudes and practices. J Fam Pract 1999;48:105-9.

29. Kuyck WG, de Wit NJ, Kuyvenhoven MM. Do doctors pay attention to the religious beliefs of their patients? A survey amongst Dutch GPs. Fam Pract 2000;17:230-2.

30. Mariotti LG, Lucchetti G, Dantas MF, et al. Spirituality and medicine: views and opinions of teachers in a Brazilian medical school. Med Teach 2011;33:339-40.

31. Cooper LA, Brown C, Vu HT, et al. How important is intrinsic spirituality in depression care? J Gen Intern Med 2001;16:634-8.

32. McCauley J, Jenckes MW, Tarpley MJ, et al. Spiritual beliefs and barriers among managed care practitioners. J Relig Health 2005;44:137-46.

33. Lucchetti G, Lucchetti AG, Badan-Neto AM, et al. Religiousness affects mental health, pain and quality of life in older people in an outpatient rehabilitation setting. J Rehabil Med 2011;43:316-22.

34. Koenig HG, King DE, Carson VB. Handbook of Religion and Health. Oxford University Press: Oxford, 2012.

35. Gonçalves JPB, Lucchetti G, Menezes PR, et al. Complementary religious and spiritual interventions in physical health and quality of life: A systematic review of randomized controlled clinical trials. PLoS One 2017;12:e0186539.

36. Hodge DR. A Systematic Review of the Empirical Literature on Intercessory Prayer. Res Soc Work Pract 2007;17:174-87.

37. Elham H, Hazrati M, Momennasab M, et al. The effect of need-based spiritual/religious intervention on spiritual well-being and anxiety of elderly people. Holist Nurs Pract 2015;29:136-43.

38. Harris JI, Usset T, Voecks C, et al. Spiritually integrated care for PTSD: A randomized controlled trial of "Building Spiritual Strength.". Psychiatry Res 2018;267:420-8.

39. Hosseini L, Lotfi Kashani F, Akbari S, et al. The Islamic Perspective of Spiritual Intervention Effectiveness on Bio-Psychological Health Displayed by Gene Expression in Breast Cancer Patients. Iran J Cancer Prev 2016;9.

40. Lynch CP, Hernandez-Tejada MA, Strom JL, et al. Association between spirituality and depression in adults with type 2 diabetes. Diabetes Educ 2012;38:427-35.

41. Lucette A, Ironson G, Pargament KI, et al. Spirituality and Religiousness are Associated With Fewer Depressive Symptoms in Individuals With Medical Conditions. Psychosomatics 2016;57:505-13

42. Lawrence RE, Curlin FA. Physicians' beliefs about conscience in medicine: a national survey. Acad Med 2009;84:1276-82.

43. Curlin FA, Hall DE. Strangers or friends? J Gen Intern Med 2005;20:370-4

44. Indrayan A, Malhotra R, Biostatistics M, et al. FL: CRC Press. Taylor \& Francis Group 2018

45. Graduation Questionnaire Data and Analysis - AAMC. Association of American Medical Colleges. http://www.aamc.org/data/gq (Accessed 7 Aug 2018).

46. Puchalski CM, Blatt B, Kogan M, et al. Spirituality and health: the development of a field. Acad Med 2014;89:10-16.

47. Ventres W, Dharamsi S, Religion B. Beyond religion and spirituality: faith in the study and practice of medicine. Perspect Biol Med 2013;56:352-61

48. Oman D. Introduction: What Should Public Health Students Be Taught About Religion and Spirituality?. Oman D, ed. Why Religion and Spirituality Matter for Public Health. Religion, Spirituality and Health: A Social Scientific Approach. Springer, Cham, 2018: 2.

49. Jacob B, White A, Shogbon A. First-year Student Pharmacists' Spirituality and Perceptions Regarding the Role of Spirituality in Pharmacy Education. Am J Pharm Educ 2017;81:108.

50. Lewinson LP, McSherry W, Kevern P. Spirituality in pre-registration nurse education and practice: A review of the literature. Nurse Educ Today 2015;35:806-14. 